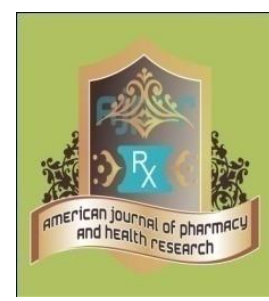

Research Article
AMERICAN JOURNAL OF PHARMACY AND HEALTH RESEARCH

www.ajphr.com

2021, Volume 9, Issue 01

ISSN: 2321-3647(online)

\title{
RP-HPLC Method Development and Validation for the Quantitative Determination of Potential Impurities of Mirabegron
}

\author{
Bharathi Tejas GJ ${ }^{1 *}$, Bhadre Gowda DG ${ }^{2}$ \\ 1. Analytica Chemie Inc, VITC, Peenya II stage, Bangalore - 570008, Karnataka, India. \\ 2.Chemistry Department, Yuvaraja's college, University of Mysore, Mysore-570005, \\ Karnataka, India
}

\begin{abstract}
The objective of the study was to develop and evaluate the reverse phase high performance liquid chromatography (RP-HPLC) method for the quantitative determination of potential impurities of Mirabegron active pharmaceutical ingredient. The method uses Puratis C18 column $(250 \times 4.6 \mathrm{~mm}$, $5 \mu \mathrm{m}$ ) with mobile phase A consisted, $20 \mathrm{mM}$ Ammonium acetate, $\mathrm{pH}$ adjusted to 4.5 and mobile phase B consisted methanol with a gradient programme. The column temperature was maintained at $25^{\circ} \mathrm{C}$ and the detection was carried out at $247 \mathrm{~nm}$. Efficient and reproducible chromatographic separation was achieved on $\mathrm{C}_{18}$ stationary phase in gradient elution profile. The newly developed HPLC method was validated according to $\mathrm{ICH}$ guidelines considering three impurities to demonstrate precision, linearity, accuracy and robustness of the method. The developed HPLC method was found to be accurate and sensitive. The correlation coefficient values are greater than 0.99 for Mirabegron and its three impurities. Detection limit and quantitation limit was 0.04ppm and $0.14 \mathrm{ppm}$ respectively, indicating the high sensitivity of the newly developed method. Accuracy of the method was established based on the recovery obtained between $99.67 \%$ and $104.98 \%$ for all impurities. The result of robustness study also indicates that the method is robust and is unaffected by small variation in chromatographic conditions. The proposed HPLC method provides reliable, reproducible, accurate and sensitive for the quantification of Mirabegron related substances.
\end{abstract}

Keywords: Mirabegron; Impurities; RP-HPLC; Validation.

*Corresponding Author Email: bharathitejas@gmail.com

Received 10 December 2020, Accepted 29 December 2020

Please cite this article as: Bharathi TG et al., RP-HPLC Method Development and Validation for the Quantitative Determination of Potential Impurities of Mirabegron. American Journal of Pharmacy \& Health Research 2021. 


\section{INTRODUCTION}

Mirabegron is a medication used to treat overactive bladder. It is less preferred to antimuscarinic medication such as oxybutynin. It is taken by mouth. Common side effects include high blood pressure, headaches, and urinary tract infections. Other significant side effects include urinary retention, irregular heart rate, and angioedema. It works by activating the $\beta 3$ adrenergic receptor in the bladder, resulting in its relaxation.

Mirabegron was approved for medical use in the United States in 2012. It is used is in the treatment of overactive bladder. It works equally well to antimuscarinic medication such as solifenacin or tolterodine. Mirabegron is a monocarboxylic acid amide obtained by formal condensation of the carboxy group of 2-amino-1,3-thiazol-4-ylacetic acid with the anilino group of (1R)-2-\{[2-(4aminophenyl) ethyl] amino\}-1-phenylethanol.

Chemical structure of Mirabegron is given in figure 1.

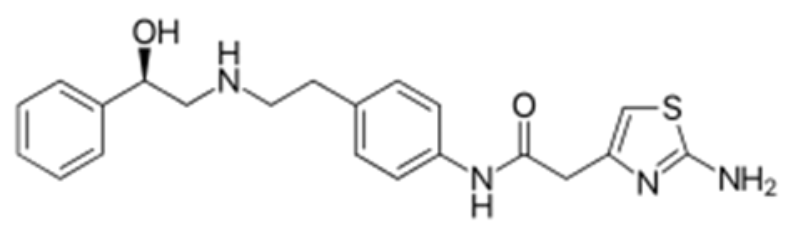

\section{Molecular weight $=396.51$ \\ Molecular formula $=\mathrm{C}_{21} \mathrm{H}_{24} \mathrm{~N}_{4} \mathrm{O}_{2} \mathrm{~S}$ \\ Figure 1: Structure of Mirabegron}

Several analytical methods have been reported to determine Mirabegron in bulk drug, formulation and in biological matrices. These methods include spectrophotometry 13 to 15 , , high performance thin layer chromatography (HPTLC) 12, high performance liquid chromatography (HPLC) 1-11, liquid chromatography tandem mass spectrometry (LC/MS) 16 and Ultra high performance liquid chromatography (UPLC) 17. Mirabegron is not an official drug in USP, EP, BP, and IP. Extensive literature survey reveals that no HPLC methods have been reported for the analysis of Mirabegron drug and its related substance. Hence it was felt necessary to develop an accurate, rapid and sensitive HPLC method for the determination of Mirabegron and its impurities.

\section{MATERIALS AND METHOD}

\section{Reagents and Chemicals}

Samples of Mirabegron and standards of Imp-1, Imp-2 and Imp-3 (Table 1) were received from Analytica Chemie Inc, Bangalore, India. HPLC grade methanol and acetonitrile was purchased from Rankem, Mumbai, India. Deionized water was prepared using a Milli-Q plus water purification system from Millipore (Bedford, MA, USA). Analytical reagent grade of Ammonium 
acetate, acetic acid, sodium hydroxide, hydrogen peroxide and hydrochloric acid were purchased from Merck India Limited (Mumbai, India).

Table 1: Potential impurities of Mirabegron

\begin{tabular}{|c|c|c|c|}
\hline $\begin{array}{l}\text { SI. } \\
\text { No. }\end{array}$ & Structure & $\begin{array}{l}\text { Mol. } \\
\text { Wt. }\end{array}$ & IUPAC name \\
\hline 1 & & 396.506 & $\begin{array}{l}\text { 2-(2-amino-1,3-thiazol-4-yl)- } \\
\text { N-[4-(2-\{[(2R)-2-hydroxy-2- } \\
\text { phenylethyl] } \\
\text { amino\}ethyl)phenyl]acetamide }\end{array}$ \\
\hline 2 & & 298.34 & $\begin{array}{l}\text { (R)-2-(2-Aminothiazol-4-yl)- } \\
\mathrm{N}-(4-(2-(2-(2-(2- \\
\text { aminothiazol-4-yl)a } \\
\text { cetamido)thiazol-4- } \\
\text { yl)acetamido)phenethyl)-N-(2- } \\
\text { hydroxy-2- } \\
\text { phenylethyl)acetamide }\end{array}$ \\
\hline 3 & & 536.67 & $\begin{array}{l}\text { (R)-2-(2-Aminothiazol-4-yl)- } \\
\text { N-(4-(2-(2-aminothiazol-4- } \\
\text { yl)acetamido)phenethyl)-N-(2- } \\
\text { hydroxy-2- } \\
\text { phenylethyl)acetamide }\end{array}$ \\
\hline 4 & & 676.83 & $\begin{array}{l}\text { (R)-2-(2-Aminothiazol-4-yl)- } \\
\mathrm{N}-(4-(2-(2-(2-(2- \\
\text { aminothiazol-4-yl)a } \\
\text { cetamido)thiazol-4- } \\
\text { yl)acetamido)phenethyl)-N-(2- } \\
\text { hydroxy-2- } \\
\text { phenylethyl)acetamide }\end{array}$ \\
\hline
\end{tabular}

\section{Instruments}

The LC method development and validation were done using Waters HPLC equipped with PDA detector. The data were collected and the peak purity of the Mirabegron peak was checked using Empower software.

\section{Chromatographic conditions}

The chromatographic separations were achieved on Puratis Eximius, C18 column ( $250 \mathrm{~mm}$ length $\times 4.6 \mathrm{~mm}$ ID with $5 \mu \mathrm{m}$ particle size. Mobile phase A consisted, $20 \mathrm{mM}$ ammonium acetate, $\mathrm{pH}$ adjusted to 4.5 and mobile phase $B$ consisted methanol with a gradient programme $\left(\mathrm{T}_{\min } \mathrm{A}: \mathrm{B}\right) \mathrm{T}_{0} 90: 10$, T10.055:45, T20.010:90, T22.010:90, T25.090:10, T30.090:10 The column temperature was maintained at $25{ }^{\circ} \mathrm{C}$ and the detection was carried out at $247 \mathrm{~nm}$. The flow rate 
was set to $1.0 \mathrm{~mL} / \mathrm{min}$. The test concentration was about $100 \mu \mathrm{g} / \mathrm{mL}$ and the injection volume was $10 \mu \mathrm{L}$. A degassed mixture of Methanol and water (8:2) was used as diluent for standard and sample preparations.

Buffers are recommended to control the $\mathrm{pH}$ stability of the mobile phase. Buffers like ammonium acetate, dipotassium hydrogen orthophosphate, potassium hydrogen phosphate, diammonium hydrogen orthophosphate, ammonium hydrogen phosphate, and its combination were studied for the Mirabegron HPLC method development. We have adjusted the $\mathrm{pH}$ of the buffer is 4.5 to get a better peak shape for all the experiments. Methanol was chosen as organic modifiers. The principle difference in the behavior of acetonitrile and methanol is that where acetonitrile forms a thick multi-molecular adsorbed layer on the surface of reverse phase adsorbent $\left(\mathrm{C}_{1}-\mathrm{C}_{18}\right.$ and phenyl phases), while methanol is adsorbed only in monomolecular fashion ${ }^{14}$. This brings a principal difference in the analyte retention mechanism in these two hydro-organic systems.

\section{Column selection}

The heart of a HPLC system is the column. Changing a column will have the greatest effect on the resolution of analytes during method development. Silica-based packing materials dominate in applications for RP separations in the pharmaceutical industry. The vast majority of RP LC separations take place on column that contain $\mathrm{C}_{18}$ bonded stationary phases due to their stability, retentively and reproducibility. In addition, these hydrophobic ligands provide the desired separation most of the time. However, screening several different types of stationary phases during method development for a particular separation is often useful because different columns usually have different selectivity for components in a sample.

Several experiments were conducted to get a baseline resolution between Mirabegron and impurities. water miscible organic solvent. Choosing a right buffer and $\mathrm{pH}$ is very critical for method development.

$\mathrm{C}_{18}$ were used in different mobile phases containing acetate buffers along with acetonitrile with $\mathrm{pH} 4.5$ Use of methanol as an organic modifier shown significance improvement in resolution between Imp-2 and Imp-3.Use of $\mathrm{RP}_{18}$ column with a $250 \mathrm{~mm}$ length $\times 4.6 \mathrm{~mm}$ ID column and $5 \mu \mathrm{m}$ particle size, use of mixture of $20 \mathrm{mM}$ ammonium acetate, $\mathrm{pH}$ adjusted to 4.5 as mobile phase $A$ and methanol as mobile phase-B was significant in achieving the desired resolution of Mirabegron and its impurities. After several trials for gradient profile, chromatographic conditions were finalized as described under section chromatographic conditions

\section{Preparation of stock solutions for method validation}


A test preparation of $1000 \mu \mathrm{g} / \mathrm{mL}$ of Mirabegron API sample was prepared by dissolving in diluent. A stock solution of impurities was prepared by dissolving $5 \mathrm{mg}$ each of Imp-1, Imp-2, Imp-3 in diluent and made up to $10 \mathrm{~mL}$ with diluent. Transferred $2.5 \mathrm{~mL}$ of each individual stock solution into a $25 \mathrm{~mL}$ volumetric flask and made up to volume with diluent. From this stock solution, standard solution of $0.5 \mu \mathrm{g} / \mathrm{mL}$ to $3.0 \mu \mathrm{g} / \mathrm{mL}$ of each impurity and $2.0 \mu \mathrm{g} / \mathrm{mL}$ to 12.0 $\mu \mathrm{g} / \mathrm{mL}$ of Mirabegron was prepared. A stock solution of Mirabegron was prepared by dissolving $25 \mathrm{mg}$ made up to $25 \mathrm{~mL}$ with diluent. Transferred $5.0 \mathrm{~mL}$ of the stock solution into a $50 \mathrm{~mL}$ volumetric flask and made up to volume with diluent. From this stock solution, standard solution of $2.0 \mu \mathrm{g} / \mathrm{mL}$ to $12.0 \mu \mathrm{g} / \mathrm{mL}$ of each impurity

\section{RESULTS AND DISCUSSION:}

\section{Method development}

The determination of the suitability of a HPLC method is based upon the level of development. However, at a minimum HPLC method should provide baseline separation of starting materials, desired products, known impurities, and expected by-products. The chromatographic conditions should also be chemically compatible with the analytes. The main objective of the HPLC method development for Mirabegron was to achieve efficient separation of impurities and a short run time method.

\section{Selection of wavelength}

The optimum wavelength of detection is the wavelength that gives the highest sensitivity for the significant related substances and minimizes the difference in response factors between those of the active pharmaceutical ingredient and the related substances. Mirabegron and its impurities give good detector response at $247 \mathrm{~nm}$, therefore the final absorption wavelength for detection was chosen at $247 \mathrm{~nm}$.

\section{Mobile phase selection}

In reverse phase chromatography, the mobile phase consists of an aqueous buffer and a non-UV active

\section{METHOD VALIDATION:}

The newly developed method was validated for sensitivity, linearity, precision and accuracy, robustness and system suitability according to ICH guidelines 20 . Validation study was carried out for Imp-1, Imp-2, Imp-3. The system suitability and selectivity were checked by injecting 12 $\mu \mathrm{g} / \mathrm{mL}$ of Mirabegron solution containing $3 \mu \mathrm{g} / \mathrm{mL}$ of all impurities monitored throughout the validation. Method validation results are summarized in Table 2. 
Table 2: Method validation summary report

\begin{tabular}{|c|c|c|c|c|c|c|c|c|}
\hline & \multicolumn{3}{|c|}{ Parameter } & Imp-1 & Imp-2 & Imp-3 & MG & \\
\hline & \multicolumn{8}{|c|}{ System suitability } \\
\hline & \multicolumn{3}{|c|}{ RT } & 10.81 & 18.65 & 19.42 & 14.87 & \\
\hline & \multicolumn{3}{|l|}{ RRT } & 0.72 & 1.25 & 1.30 & 1 & \\
\hline & \multicolumn{3}{|l|}{ Rs } & - & 22.01 & 19.76 & 3.95 & \\
\hline & \multicolumn{3}{|l|}{$\mathrm{N}$} & 49265 & 117444 & 153273 & 171111 & \\
\hline & \multicolumn{3}{|l|}{$\mathrm{T}$} & 1.03 & 1.07 & 1.05 & 1.04 & \\
\hline & \multicolumn{8}{|c|}{ Linearity } \\
\hline & \multirow{2}{*}{\multicolumn{3}{|c|}{$\mathrm{r}$}} & 0.9996 & 0.9993 & 0.998 & 0.9996 & \\
\hline & & & & 15568.64 & 824769.3 & 45823523.6 & 939659.51 & \\
\hline & \multicolumn{8}{|c|}{ (1) } \\
\hline & \multicolumn{3}{|c|}{ Detection limit (ppm) } & 0.07 & 0.07 & 0.02 & 0.01 & \\
\hline & \multicolumn{3}{|c|}{ Quantitation limit (ppm) } & 0.12 & 0.04 & 0.21 & 0.06 & \\
\hline & \multicolumn{8}{|c|}{ Precision } \\
\hline & $\% \mathrm{RS}$ & $(\mathrm{n} 6)$ & & 2.01 & 1.09 & 1.43 & 0.22 & \\
\hline & \multicolumn{8}{|c|}{ Repeatability (intraday) } \\
\hline & \multicolumn{3}{|c|}{$\% \operatorname{RSD}(\mathrm{n} 6)$} & 3.82 & 0.98 & 1.98 & 1.57 & \\
\hline & \multicolumn{8}{|c|}{ Intermediate precision (inter day) } \\
\hline & \multicolumn{3}{|c|}{$\% \operatorname{RSD}($ n 6$)$} & 2.97 & 0.72 & 0.93 & 0.35 & \\
\hline & \multicolumn{8}{|c|}{ Accuracy at $50 \%$ level (n 3) } \\
\hline & \multicolumn{3}{|c|}{ Amount added $(\%)$} & 0.53 & 0.53 & 0.53 & 13.30 & \\
\hline & \multicolumn{3}{|c|}{ Amount recovered $(\%)$} & 0.517 & 0.5131 & 0.5115 & 12.715 & \\
\hline & \multicolumn{3}{|c|}{$\%$ Recovery } & 103.61 & 104.54 & 104.98 & 104.63 & \\
\hline & \multicolumn{8}{|c|}{ Accuracy at $100 \%$ level (n 3) } \\
\hline & \multicolumn{3}{|c|}{ Amount added $(\%)$} & 1.05 & 1.05 & 1.05 & 25.95 & \\
\hline & \multicolumn{3}{|c|}{ Amount recovered (\%) } & 1.03 & 1.02 & 1.023 & 25.36 & \\
\hline & \multicolumn{3}{|c|}{$\%$ Recovery } & 102.26 & 102.94 & 103.24 & 102.34 & \\
\hline & \multicolumn{8}{|c|}{ Accuracy at $150 \%$ level (n 3) } \\
\hline & Amou & added $(\%)$ & & 1.54 & 1.54 & 1.54 & 38.82 & \\
\hline & Amou & recovered $(\%$ & & 1.55 & 1.53 & 1.53 & 37.703 & \\
\hline & $\% \operatorname{Re}$ & very & & 99.67 & 100.56 & 100.59 & 102.96 & \\
\hline Stress con & lition & Time(min) & $\operatorname{Temp}\left({ }^{\circ} \mathbf{C}\right)$ & $\begin{array}{l}\text { \% Assay } \\
\text { substance }\end{array}$ & of active & $\begin{array}{l}\% \text { of Deg } \\
\text { products }\end{array}$ & radation & $\begin{array}{l}\% \\
\text { Area }\end{array}$ \\
\hline $\begin{array}{l}\text { Acid Hydr } \\
(1 \mathrm{~N} \mathrm{HCl})\end{array}$ & lysis & 120 & 60 & 104.2757 & & 1.39 & & 98.61 \\
\hline $\begin{array}{l}\text { Basic Hyd } \\
(1 \mathrm{~N} \mathrm{NaOH}\end{array}$ & olysis & 120 & 60 & 90.62859 & & 2.34 & & 97.66 \\
\hline $\begin{array}{l}\text { Oxidation } \\
\left(10 \% \mathrm{H}_{2} \mathrm{O}\right.\end{array}$ & & 120 & 60 & 55.47937 & & 25.70 & & 74.30 \\
\hline $\begin{array}{l}\text { Hydrolysis } \\
\left(60^{\circ} \mathrm{C}\right)\end{array}$ & & 120 & 60 & 101.2761 & & 0.1 & & 99.99 \\
\hline $\mathrm{UV}(254 \mathrm{n}$ & & 3600 & - & 105.5835 & & 0.1 & & 99.99 \\
\hline
\end{tabular}

\section{Limit of detection (LOD) and limit of quantitation (LOQ)}

The limit of detection and limit of quantitation were determined for trimipramine maleate and for each of the related substances as per ICH Q2 $\mathrm{R}_{1}$ guideline. The LOD and LOQ for Imp-1, Imp-2, 
Imp-3 and Mirabegron were estimated at a signal-to-noise ratio of 3:1 and 10:1, respectively by injecting a series of diluted solutions with known concentration. The limit of detection and the limit of quantitation for Imp-1, Imp-2, Imp-3 and Mirabegron were about 0.07, $0.07 \& 0.02$ ppm \& $0.12,0.04 \& 0.21 \mathrm{ppm}$ respectively. Precision study was also carried at the LOQ level by injecting six individual preparations of all impurities and the relative standard deviation for LOQ concentration for all impurities were below $5 \%$.

\section{Linearity and range}

The linearity of an analytical procedure is its ability (within a given range) to obtain test results, which are directly proportional to the concentration of all impurities. The range of the method was from LOQ to $0.21 \mu \mathrm{g} / \mathrm{mL}$ of the analyte concentration $(100 \mu \mathrm{g} / \mathrm{mL})$.

\section{Precision}

Precision of the method was studied for method precision and intermediate precision. Method precision was checked by injecting six individual preparations of $(100 \mu \mathrm{g} / \mathrm{mL})$ Mirabegron spiked with $0.5 \mu \mathrm{g} / \mathrm{mL}$ of each impurity. In the intermediate precision study, the similar procedure of method precision was carried out by a different day. \% RSD of areas of each impurity was within 5.0, confirming good precision at low level of the developed analytical method.

\section{Accuracy}

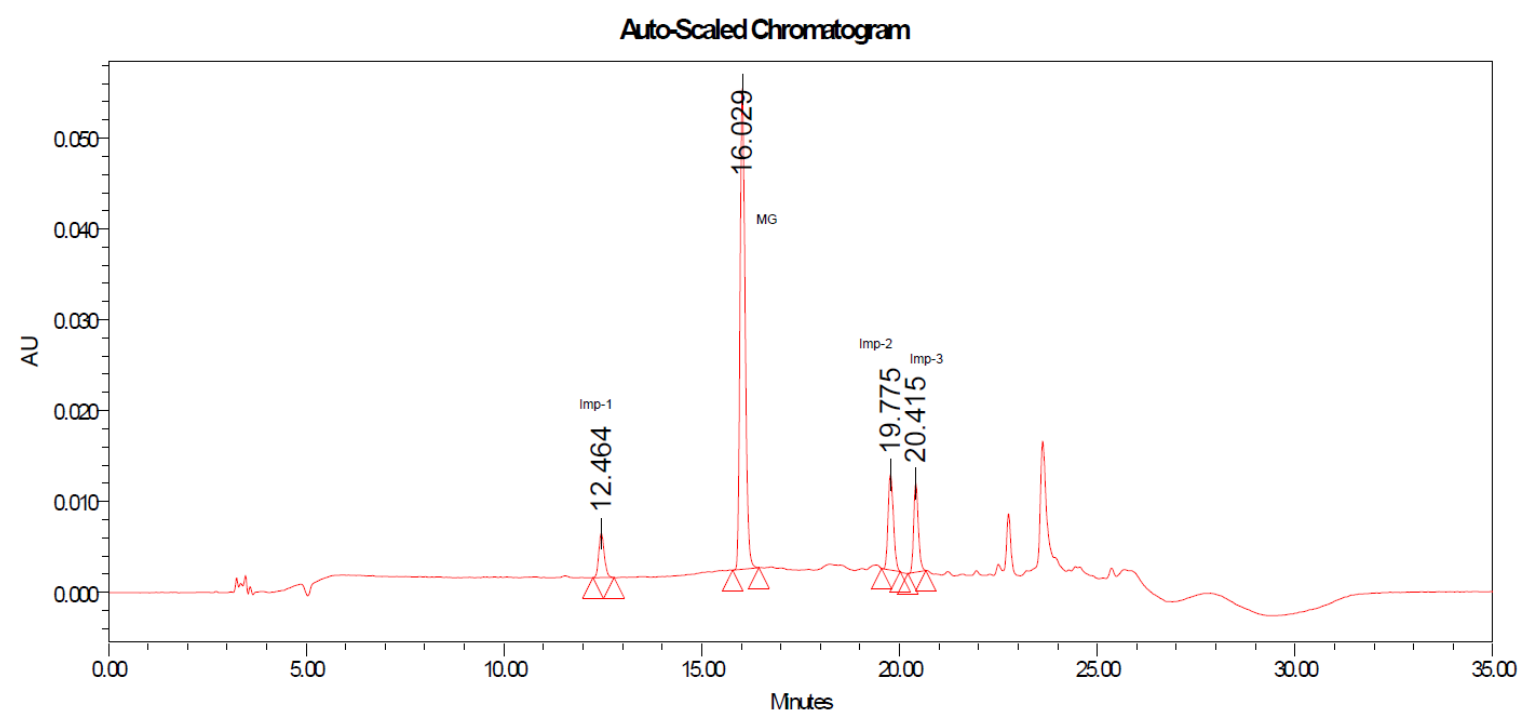

Figure 2: Chromatogram of Mirabegron spiked with impurities

The accuracy of an analytical procedure expresses the closeness of agreement between the value, which is accepted either as a conventional true value or an accepted reference value and the value found. The accuracy of the method was evaluated in triplicate $50 \%$ level $(0.51 \mu \mathrm{g} / \mathrm{mL}), 100 \%$ level $(1.02 \mu \mathrm{g} / \mathrm{mL})$ and $150 \%$ level $(1.53 \mu \mathrm{g} / \mathrm{mL})$. The percentage recovery of all impurities in drug substance has been calculated. Chromatogram of Mirabegron spiked with three impurities was 
depicted in Figure 2. concentration of the analyte in the sample. A linearity test solution for related substance method was prepared by diluting the impurity stock solution to the required concentrations. was subjected to linear regression analysis method. Calibration equation obtained from regression analysis was used to calculate the corresponding predicted responses. The residuals and sum of the residual squares were calculated from the predicted responses. The correlation coefficient obtained was greater than 0.99 for all impurities. The result showed an excellent correlation between the peak and its impurities

\section{Robustness}

To determine the robustness of the method, experimental conditions were deliberately changed and the resolution between closely eluting peaks, Imp-2 and Imp-3 were evaluated. Close observation of analysis results of deliberately changed chromatographic conditions viz; flow rate $(0.2 \pm 0.05 \mathrm{~mL} / \mathrm{min}), \mathrm{pH} 4.5 \pm 0.2$ and column temperature $\left(25 \pm 2{ }^{\circ} \mathrm{C}\right)$ shown no significant change in relative retention time for all impurities in spiked sample illustrating the robustness of the method.

\section{Solution stability and mobile phase stability}

The solution stability of trimipramine maleate and its related impurities was carried out by leaving both spiked and unspiked sample solutions in tightly capped HPLC vials for $72 \mathrm{~h}$ in an auto sampler. Content of each impurity was determined against freshly prepared standard solution. No significant changes were observed in the content of any of the impurities. The solution stability and mobile phase stability experiment data confirms that the sample solutions and mobile phase used during related substance determination were stable for at least 72 hour.

\section{CONCLUSION:}

The developed HPLC method provides reliable, reproducible, accurate and sensitive for the quantification of trimipramine maleate related substances. This newly developed method has been validated as per regulatory requirements and has shown acceptable precision, accuracy and adequate sensitivity. This method can be used for the routine analysis of Mirabegron active pharmaceutical ingredient related substances.

\section{ACKNOWLEDGEMENTS:}

The author is thankful to the management of Analytica Chemie Inc for providing necessary facilities.

\section{REFERENCES:}

1. B. MOUNIKA et al; Determination and validation of RP-HPLC method for the estimation of Mirabegron in tablet dosage form; International Journal of Current Pharmaceutical 
Research, Vol 9, Issue 5, 2017

2. B. V. Rami Reddy, et al; Development and Validation of a Speci $\square$ c Stability Indicating High Performance Liquid Chromatographic Methods for Related Compounds and Assay of Solifenacin Succinate; Journal of Chemistry Volume 2013, Article ID 412353

3. Gopal Rao et al; Analytical method development and validation of Mirabegraon by RPHPLC Method; Journal of Pharmacy Research 2017,11(6),682-685

4. Mehdi Rezaei et al; RP-HPLC Method Development and Validation for the Quantitative Estimation of Mirabegron in Extended-Release Tablets; Journal of Medicinal and Chemical Sciences 2018 (1) 36-40 J. Med. Chem. Sci.

5. Jyothsna et al; Method Development and Validation of Mirabegron in Bulk Drug and Pharmaceutical Dosage Form; Journal of Pharmacy and Biological Sciences (Volume 13, Issue 1 Ver. III (Jan. - Feb. 2018), PP 78-83

6. R. Spandana et al; Analytical method development and validation for the estimation of Mirabegron in bulk and pharmaceutical dosage form by RP-HPLC; Indo American journal of pharmaceutical research

7. Fan Zhou1 et al; Liquid Chromatographic Separation and Thermodynamic Investigation of Mirabegron Enantiomers on a Chiralpak AY-H Column; Journal of Chromatographic Science 2015; 53:1361-1365

8. Enantiomers on a Chiralpak AY-H Column; Journal of Chromatographic Science 2015; 53:1361-1365

9. DING et al; Determination of related substances in mirabegron by HPLC; Source: Chinese Journal of Pharmaceutical Analysis, Volume 36, Number 8, 2016, pp. 1439-1445(7)

10. DING et al ; Determination of related substances in mirabegron by HPLC; Chinese Journal of Pharmaceutical Analysis; 2016-08

11. Yehia, Ali et al; Comparison of Two Stability-Indicating Chromatographic Methods for the Determination of Mirabegron in Presence of Its Degradation Product; Chromatographia, Volume 80 (1) - Nov 29, 2016 ICH Guidelines, Q2 (R1), Validation of analytical procedures: test and methodology, November, 2005

12. Shah Dimal et al; High-Performance Thin-Layer Chromatographic Method for the Estimation of Mirabegron and Solifenacin Succinate Used in the Treatment of Overactive Bladder Syndrome 
13. Panchumarthy Ravisankar et al; Validated UV spectrophotometric method for quantitative determination of Mirabegron in bulk and Pharmaceutical dosage form; Scholars Research Library Der Pharmacia Lettre, 2016, 8 (14):96-103

14. Deshmukh et al; First Direct Isolation of Stable -Form Crystals of Mirabegron, a Selective $\square$ 3-Adrenoceptor Agonist; Acta Chim. Slov. 2017, 64, 461-466 461

15. G. Raveendra Babu et al; Stability indicating simultaneous estimation of Vildagliptin and Mirabegron in bulk and pharmaceutical dosage form by using UV spectroscopy; World Journal of Pharmacy and pharmaceutical sciences. Volume 6, Issue 5, 912-925 Research Article

16. Teijlingen et al.; Development and validation of LC-MS/MS methods for the determination of mirabegron and its metabolites in human plasma and their application to a clinical pharmacokinetic study ; J Chromatogr B Analyst Technol Biomed Life Sci. 2012 Mar 1;887-888:102-11.

17. Pentapuri Saipriya et al; To Develop A New RP-UPLC Method For Estimation Of Mirabegron In Pharmaceutical Dosage Forms With Forced Degradation Studies; Journal of Global Trends in Pharmaceutical Sciences

AJPHR is

Peer-reviewed

monthly

Rapid publication

Submit your next manuscript at

editor@ajphr.com / editor.ajphr@gmail.com 